первое десятилетие XXI века : авторефф. дис. ... канд. пед. наук. Чита, 2010. 23 с.

4. Козлова Л. А. Обновление уклада школьной жизни : дис. ... канд. пед. наук. Красноярск, 2003. 24 с.

5. Вачкова С. Н. Уклад школы как педагогическая категория и феномен действительности // Вестн. Балт. федерал. унта им. И. Канта. 2013. № 5. С. 54-59. URL: https://cyberleninka. ru/article/n/uklad-shkoly-kak-pedagogicheskaya-kategoriya-ifenomen-deystvitelnosti (дата обращения: 08.04.2020).

6. Корсакова Т. В. Научно-педагогические основы формирования уклада школьной жизни : автореф. дис. ... д-ра пед. наук. Калуга, 2013. 40 c.

7. Philip W. J. Life in Classrooms. New York : Teachers College Press, 1990. 183 p.

8. Marsh C. J. Perspectives: Key Concepts for Understanding Curriculum 1. New Edition. London; Washington : The Falmer Press, 1997. 212 p.

9. Bergenhenegouwen G. Hidden Curriculum in the University // Higher Education. 1987. Vol. 16. P. 535-543.

УДК 372.881.161.1

Науч. спец. 13.00.08

DOI: $10.36809 / 2309-9380-2020-27-120-123$

\section{АДАПТАЦИЯ ПРОФЕССИОНАЛЬНО ОРИЕНТИРОВАННЫХ ТЕКСТОВ ДЕЛОВОГО СТИЛЯ В ВОЕННОМ ВУЗЕ: ПРОБЛЕМЫ И ПУТИ РЕШЕНИЯ}

В статье рассматриваются противоречия между уровнем сложности текстов профессионально-деловой военной сферы (уставы, распоряжения, приказы) и необходимостью их освоения с начала обучения в военном вузе. Определены возможности адаптации таких текстов, методы освоения, пути представления. Обоснована необходимость контактов преподавателей русского языка как иностранного и преподавателей военных кафедр, офицеров-воспитателей.

Ключевые слова: русский язык как иностранный, адаптация текста, текст официально-делового стиля, военный подъязык.
10. Yaghoob N., Hossein M., Maral A. Hidden Curriculum Effects on University Students' Achievement // Procedia Social and Behavioral Sciences. 2014. № 114. P. 798-801.

11. Ghasem B., Fereydoon A., Seyyed H. S. Quality Indicators of Hidden Curriculum in Centers of Higher Education // Procedia - Social and Behavioral Sciences. 2011. № 30. P. 1657-1661.

12. Silveira G. L. [et al.]. "Speed up"! The Influences of the Hidden Curriculum on the Professional Identity Development of Medical Students // Health Professions Education. 2019. Vol. 5, Iss. 3. P. 198-209. URL: https://www. sciencedirect.com/science/article/pii/S2452301118301019 (дата обращения: 12.04.2020).

13. University Life Uncovered: Making sense of the Student Experience : monograph. SWAP, 2008. URL: https://uwerepository.worktribe.com/output/1017250 (дата обращения: 12.04.2020).

(C) Алексеева Т. Ю., 2020 V. V. Bestsennaya, E. V. Fedyaeva, R. L. Vorobyov

\title{
ADAPTATION OF PROFESSIONALLY ORIENTED TEXTS OF FORMAL LANGUAGE IN A MILITARY UNIVERSITY: PROBLEMS AND SOLUTIONS
}

The article discusses the contradictions between the level of complexity of the texts of the professional field (charters, orders, instructions) and the necessity to master them from the beginning of the training at a military university. The possibilities of adapting such texts, developmental methods, ways of presentation were determined. The need for the contacts between teachers of Russian as a foreign language, the teachers of the military departments and the educational officers was substantiated.

Keywords: Russian as a foreign language, text adaptation, official style text, military sublanguage.

Современный словарь методических терминов и понятий определяет адаптацию текста как «упрощение, приспособление, облегчение или усложнение текста в соответствии с уровнем языковой компетенции учащихся» [1, с. 10]. При адаптации создается такое сообщение, которое ориентировано на определенного адресата, его знания в той области, к которой относится сообщение, его языковую и культурологическую компетенции. Такое сообщение называют адаптированным текстом, в отличие от аутентичного. Выделяют сильную адаптацию текста - общее качественное изменение речевой структуры текста, среднюю - внесение существенных изменений за счет мелких сокращений и синонимических замен трудных мест и слабую - сокращение крупных блоков текста с сохранением содержательного ядра и выделением определенных содержательных линий. Кроме того, существует термин «условная адаптация» - вставка комментариев к сложным для иностранца понятиям, описанным в тексте.

Упрощать тексты в учебных целях начали в методике преподавания английского языка как иностранного в 1930-х гг. Одним из методистов, работавших над данной проблемой, был Ч. Огден, который создал так называемый Basic English, в основе которого лежало прежде всего лексическое упрощение. Дж. Пальмер и А. Хорнби создавали тексты-плато на базе лексического минимума, состоявшего из 1000 слов. Далее идея упрощения текстов воплощалась 
М. Уэстом, разработавшим методику составления книг для чтения с использованием системы уровней сложности, опирающихся на лексические и грамматические минимумы. М. Уэст разделял уровни в 1000, 1500, 2000 и 3000 слов. Отечественные специалисты в области методики преподавания русского языка как иностранного ориентировались как на опыт европейских коллег, так и искали свои пути решения проблемы. В 1967 г. А. А. Вейзе продолжил исследования в этой области, разработав анализ единиц и методы адаптации, а также уровни адаптации [2].

В наше время издательство «Златоуст» продолжает традиции, выпуская серию «Библиотека Златоуста». Серия включает адаптированные тексты для 5 уровней владения русским языком как иностранным. Это произведения классиков русской литературы, современных писателей, публицистов, журналистов, а также киносценарии. I уровень основан на минимуме в 760 слов, наиболее часто встречающихся в учебниках русского языка для начинающих. II-V уровни ориентируются на лексические минимумы, разработанные для Российской государственной системы тестирования по русскому языку. Каждый выпуск снабжен вопросами, заданиями и полным словарем, в котором выделены слова, выходящие за пределы минимума: I - 760 слов, II - 1300 слов, III - 1500 слов, IV - 2300 слов, V - 3000 слов.

Для удобства читателей цвета обложки соответствуют уровню адаптации: зеленый - сильная адаптация («Трудно быть богом» А. и Б. Стругацких); синий («Кавказский пленник» - рассказы известных русских писателей о войне на Кавказе) и фиолетовый («По страницам Пушкина») - средняя адаптация; светло-желтый («Азазель», «Левиафан» Б. Акунина) - слабая адаптация); оранжевый - условная адаптация, наличие комментариев («Ника» В. Пелевина) [3]. Адаптация текста находит отражение не только в преобразованиях внешней формы, но и в содержательном отношении. Выделяют следующие модели содержательной адаптации текста: симплификация (упрощение содержания), денотатная экспликация (объяснение терминологии) и амплификация (толкование специфичной ситуации).

Продолжаются поиски решений адаптации текстов с применением информационных технологий. Известно, что идет работа по созданию программы автоматизированного определения сложности текста, которая будет не только определять уровень загруженного текста, но и адаптировать текст для заданного пользователем уровня, что должно оказать неоценимую услугу преподавателю при подготовке дидактических материалов к занятиям.

Таким образом, при адаптации текста как бы балансируют между стремлением упростить текст за счет использования более общеупотребительной лексики и более простых грамматических конструкций и вместе с тем пытаются передать стиль автора (в случае с художественным текстом) и идею хотя бы в общих чертах. Отметим, что в отечественной методике преподавания русского языка как иностранного наиболее освещены вопросы адаптации художественных текстов [4; 5; 6; 7; 8; 9], в то время как адаптация текстов официальноделового стиля остается за рамками исследований.

Между тем в военных вузах РФ, как правило, учатся иностранные военнослужащие, у которых основную тексто- вую базу составляют тексты, обслуживающие повседневную жизнь военнослужащего (уставы, рапорты, доклады, инструкции и т. д.), т. е. тексты делового стиля.

Профрессионально ориентированные тексты рассчитаны на российского курсанта, сложны в лексическом и грамматическом аспектах даже для носителя языка, так как представляют собой образцы официально-делового стиля. Отсюда наличие клише, строгая организация и другие лексические и грамматические особенности делового стиля.

Естественно предположить, что данные тексты нужно адаптировать для иностранцев, обучающихся в военном вузе РФ. Однако попытки преподавателей русского языка как иностранного часто встречают не просто непонимание, но даже агрессию со стороны преподавателей военных дисциплин и офицеров, работающих с иностранцами. Адаптированный текст понимается как «испорченный», неправильный, отошедший от канонов. В этом случае можно говорить о «военной языковой картине мира» и о языковом сознании военного человека, о профессиональной речевой деформации $[9 ; 10]$. Военные «цепляются» за форму, боятся заменить хотя бы одно слово синонимом. На наш взгляд, любые тексты можно и нужно адаптировать для лучшего понимания на этапе восприятия. При адаптации текстов делового стиля (военных) преподаватели русского языка работают в прежде всего в контакте с офицерами-воспитателями специального факультета. Уже второй год в общежитии Омского филиала Военной академии материально-технического обеспечения, где проживают курсанты-иностранцы, документация для ознакомления представлена в двух вариантах - аутентичном и адаптированном. На этаже, где проживают курсанты подготовительного (нулевого) курса, распоряжения, правила, фрагменты уставов представлены в сильно адаптированном варианте (уровни A1, A2). Для первокурсников имеются варианты средней адаптации (В1). Со второго курса курсанты достигают достаточного уровня, чтобы читать документацию в неадаптированном виде.

Рассмотрим варианты адаптации текстов по темам «Физическая подготовка военнослужащих», «Строевая подготовка», расположенных на стендах в казарме. Слева дан аутентичный текст для российских курсантов, справа - его адаптированные варианты для трех возможных уровней владения русским языком по международной системе.

При анализе текстов выделяются военные словосочетания (клише), с которыми необходимо познакомить курсантов на занятиях по русскому языку. На наш взгляд, для полного понимания их эффективнее перевести на родной язык. Выделяются лексико-тематические группы «командный состав (начальство)», «мероприятия и их элементы». Это следующая лексика: старшина курса, курсовой офицер, начальник курса; национальная группа, подразделение; распорядок дня, утренняя физическая зарядка, форма одежды, утренний строевой тренаж, строевая песня, торжественный марш, строевая подготовка.

При переводе эффективнее привлекать иностранных курсантов-старшекурсников, уже имеющих фоновые знания по специальности и владеющих русским языком на достаточном уровне. 


\section{Текст «Физическая зарядка»}

\begin{tabular}{|l|l|}
\hline Утренняя (А2) физическая & Уровень А1 \\
(А2) зарядка (А2, допол.) & Курсанты делают зарядку \\
проводится (В1) ежеднев- & каждый день. \\
но (В1) согласно (B2) рас- & Время: 6:40-7:10. \\
порядку дня (A2, допол.) & В воскресенье нет зарядки \\
\cline { 2 - 2 } института (A1) в период & Уровень А2 \\
с 6:40 до 7:10, кроме (B1) & Курсанты делают утрен- \\
воскресенья (A1) & нюю фризическую зарядку \\
& каждый день по распорядку \\
& дня. Время: 6.40-7.10. \\
& В воскресенье зарядки нет \\
\cline { 2 - 2 } & Уровень В1 \\
& Утренняя физическая \\
& зарядка проводится еже- \\
& дневно по распорядку дня \\
& института с 6.40 до 7.10, \\
& кроме воскресенья \\
\hline
\end{tabular}

Имеются (В1) 4 варианта

(B1) утренней (A2) фиизической (A2) зарядки (A2, допол.)

\section{Уровень А2 \\ Есть 4 утренних физичес- ких зарядки}

\begin{tabular}{|l|l|}
\hline Варианты включают & Уровень А2 \\
в себя (C1) различные & Упражнения и бег (сколько \\
(В2) упражнения (A1) & километров надо бежать) \\
и дистанции (C1) & разные для каждого \\
& варианта \\
\hline
\end{tabular}

\begin{tabular}{|l|l|}
\hline Утреннюю физическую & Уровень А2 \\
зарядку проводит старшина & Обычно старшина курса \\
курса (А2, допол.), 2 раза & организует утреннюю \\
в неделю проводит & физическую зарядку. \\
курсовой офицер & 2 раза в неделю это \\
(А2, допол.) и начальник & делает курсовой офицер \\
курса (А2, допол.). & и начальник курса \\
\hline
\end{tabular}

\begin{tabular}{|l|l|}
\hline В зависимости от (С1) тем- & Уровень А1 \\
пературы (А1) устанавли- & (дается картинка с формой \\
вается (B2) форма одежды & одежды) \\
(A2, допол.) на утреннюю & Температура__, форма \\
(A2) фризическую (А2) & №__ \\
\cline { 2 - 2 } зарядку (А2, допол.) & Уровень В1 \\
& Форма одежды для утрен- \\
& ней физической зарядки \\
& зависит от температуры \\
\hline
\end{tabular}

\begin{tabular}{|l|l|}
\hline При температуре (В1, & Уровень А2 \\
терм.) от - 11 вместо утрен- & Если холодно (-11, -12, \\
ней (А2) фризической (A2) & $-13 . .)$, утренней физичес- \\
зарядки (A2, допол.) про- & кой зарядки нет, курсанты \\
водится (B1) прогулка (B1), & гуляют \\
форма одежды (A2) указана & \\
(С1) в приложении (C1) & \\
\hline
\end{tabular}

\section{Текст «Строевая подготовка»}

\begin{tabular}{|c|c|}
\hline $\begin{array}{l}\text { Строевая подготовка (А2, } \\
\text { допол.) на подготовитель- } \\
\text { ном курсе (B1) проводится } \\
\text { (B1) только (A2) во время } \\
\text { (B1) утренних строевых } \\
\text { тренажей (B1, допол.), кото- } \\
\text { рые (В1) установлены (C1) } \\
\text { в распорядке дня (A2, до- } \\
\text { пол.) }\end{array}$ & \begin{tabular}{|l} 
Уровень А2 \\
Курсанты нулевого курса \\
занимаются строевой под- \\
готовкой только утром. \\
Уровень В1 \\
Строевая подготовка на \\
подготовительном курсе \\
проводится только утром \\
по распорядку дня
\end{tabular} \\
\hline
\end{tabular}

\begin{tabular}{|l|l|}
\hline Строевые приемы отраба- & Уровень А2 \\
тываются по графику: & Тренировка строевых \\
вторник - «отход, подход & приемов. \\
к начальнику»; & Вторник - «отход, подход \\
среда, четверг - «про- & к начальнику». \\
хождение в составе & Среда, четверг - \\
подразделения торжес- & «Российский марш \\
твенным маршем и про- & и строевая песня» (каждый \\
хождение с песней» & курс). \\
(у каждого курса своя & Пятница, суббота - \\
строевая песня); & «Национальный марш \\
пятница, суббота - «про- & и национальная песня» \\
хождение в составе наци- & (национальная группа) \\
ональных групп согласно & \\
своему строевому уставу & \\
торжественным маршем & \\
с национальной песней». & \\
Строевую подгтовку про- & \\
водит начальник курса или & \\
курсовой офицер & \\
\hline
\end{tabular}

Кроме того, на занятиях по русскому языку как иностранному в рамках тем «Стилистика: официально-деловой стиль речи» преподаватели работают с текстами инструкций, указаний, приказов, занимаясь их адаптацией вместе с курсантами.

Текст делового, как и любого другого, стиля на занятиях должен быть дидактически обработан - снабжен заданиями трех типов: предтекстовыми, притекстовыми и послетекстовыми. Данные задания создаются на основе структурного или коммуникативного подходов. Например, при изучении инструкций дневальному предтекстовые задания при структурном подходе будут включать списки слов и словосочетаний, которые необходимо перевести, проанализировать с точки зрения формы, а при коммуникативном - курсантам будут заданы вопросы о личном участии в дежурстве (А ты был в наряде? Ты был дежурным или дневальным? Что ты должен был делать, а чего делать нельзя?).

Притекстовые задания заключаются в поисковом чтении, важно, что именно предлагается искать: при структурном подходе будут включать задания на нахождение фактической информации, при коммуникативном - анализ проблемных точек текста. Как показывает практика, эффрективны задания на поиск синонимичных фраз. Звучат они следующим образом: 
Найдите фразы, которые наиболее близки по смыслу к положению из инструкции дневальному:

1. Никуда не отлучаться из помещения курса без разрешения дежурного по курсу.

а) Дневальный может уйти с поста только если ему разрешит дежурный по курсу.

б) Дневальный не может уйти с поста.

в) Дневальный может уйти с поста, когда захочет.

2. Не позволять военнослужащим в холодное время, особенно ночью, выходить из помещения неодетыми.

а) Если ты дневальный, ты можешь выходить из казармы без куртки.

б) Если ты дневальный, ты должен одевать своих товарищей.

в) Если ты дневальный, ты не должен разрешать курсантам выходить зимой на улицу без куртки и шапки.

3. Немедленно докладывать дежурному по курсу обо всех происшествиях на курсе, о нарушении уставных правил взаимоотношений между военнослужащими роты, замеченных неисправностях.

а) Говорить дежурному, если курсанты подрались, если украли вещи; если не работает электричество, есть проблемы с водой.

б) Рассказывать дежурному о новостях в мире и родной стране.

в) Не говорить ничего дежурному, мужчина должен решать свои проблемы сам.

Послетекстовые задания при структурном подходе вопросы по содержанию, пересказ или пересказ с трансформацией; при коммуникативном подходе нужно сделать так называемый шаг за пределы текста: а как проходит дневальная служба у вас в стране? Расскажите вашим друзьям на родине, как вы дежурите в России; посмотрите отрывок из сериала «Кадетство», что случилось с дневальным во время наряда? Вы офицер, придумайте диалог с героем видеофрагмента (разбор ситуации, когда дневальный засыпает во время несения наряда) [7].

Таким образом, в результате исследования можно сфрормулировать следующие выводы:

1. Основная проблема адаптации текстов делового стиля в военном вузе связана с восприятием их как «канонических», предназначенных для заучивания наизусть, возможно, даже без понимания. Адаптировать текст для военного сознания - значит испортить его. Дополнительная проблема: даже если офицер-воспитатель понимает необходимость адаптации, у него нет умений и навыков в этом виде деятельности, соответственно, необходимо сотрудничество и взаимодействие в вопросах освоения текстов делового стиля.

2. Информационные стенды должны иметь 2 вида текстов: аутентичные и адаптированные, при этом вторые могут быть разной степени адаптации: для начинающих изучать русский язык (сильная адаптация), для продолжающих изу- чать русский язык (средняя адаптация). Возможно применение цветовой символики: документы сильной адаптации с зеленым значком (рамкой), средней - с синим значком (рамкой).

3. При работе с лексическим минимумом военного делового стиля предлагается задействовать в качестве переводчиков иностранных военнослужащих старших курсов. При имеющейся возможности распечатывать брошюры «Ты учишься в Российской Федерации» с приложением основной военной лексики, которая будет необходима для несения нарядов, текстов для повседневной жизни в институте (рапорты по прибытию - убытию, рапорт на занятии и т. д.), лексико-тематических групп (звания, лексика спортивных мероприятий и т. д.).

1. Азимов Э. Г., Щукин А. Н. Современный словарь методических терминов и понятий. Теория и практика обучения языкам. М. : Русский язык. Курсы, 2018. 496 с.

2. Вейзе А. А. Методика адаптации текстов художественных произведений в учебных целях : дис. ... канд. пед. наук. М., 1967. 198 с.

3. Каталог // Издательство «Златоуст». URL: http://www. zlat.spb.ru/catalog5_4.html (дата обращения: 11.01.2020).

4. Дьякова А. А. Интердискурсивная адаптация текста : автореф. дис. ... канд. филол. наук. Волгоград, 2009. 20 с.

5. Зайцева А. Р. Принципы адаптации художественных текстов в преподавании РКИ // Современная парадигма гуманитарных исследований: проблемы филологии и культурологи : сб. материалов Междунар. науч.-практ. конф. I отв. ред. С. Г. Григоренко. М. : Перо, 2018. С. 64-68.

6. Коротышев А. В. «Матрица адаптации» как комплекс приемов для отбора и адаптации художественных текстов в аспекте РКИ // Мир русского слова. 2014. № 1. С. $106-113$.

7. Федяева Е. В., Бесценная В. В. Обучение профессионально-ориентированному аудированию на занятия РКИ (на материале видеофрагментов сериала «Кадетство») // Актуальные вопросы описания и преподавания русского языка как иностранного/неродного : материалы Междунар. науч.практ. интернет-конф. / под общ. ред. Н. В. Кулибиной. М. : Гос. ин-т рус. яз. им. А. С. Пушкина, 2018. С. 971-975.

8. Первухина С. В. Структурно-семантические и дискурсивно-прагматические характеристики адаптированного текста : автореф. дис. ... д-ра филол. наук. Ростов н/Д, 2015. 39 c.

9. Попова О. В. Адаптация текста к новым дискурсивным условиям // Ом. науч. вестн. 2011. № 3 (98). С. 111-113.

10. Фесенко О. П. Каким должен быть военный инженер, или К вопросу о сложности обучения курсантов военного вуза: взгляд гуманитария // Национальный приоритеты России. Сер. 1. Наука и военная безопасность. 2017. № 1 (8). С. 175-176. 2020

(C) Бесценная В. В., Федяева Е. В., Воробьёв Р. Л., 